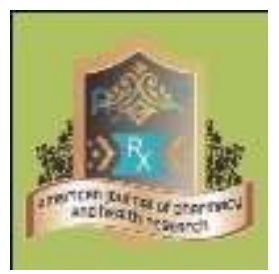

Research Article AMERICAN JOURNAL OF PHARMACY AND HEALTH RESEARCH www.ajphr.com

2018, Volume 6, Issue 02

ISSN: 2321-3647(online)

\title{
Social Anxiety and Problematic Internet Use among University Students
}

\author{
Rabina Debbarma*, G. Umadevi** \\ Department of Psychology, Annamalai University.
}

ABSTRACT

This study was conducted to find out the relationship between social anxiety and problematic internet use among university students. It was also tried to find out the difference between demographic variables like gender and locality. 200 university students were selected from Tripura University, in Tripura State through simple random sampling technique. Problematic Internet Use Questionnaire (Tatcher \& Goolam, 2005) and Social Anxiety Questionnaire for Adults (SAQ-A30) developed by Callallo, Salazar, Irurtia, Arias and CISO-A Research Team, 2010 were used for data collection. The obtained results revealed that there is a positive relationship between problematic internet use and social anxiety. Males were found to have more social anxiety and problematic internet use. Further it is found that there is no significant different between Problematic Internet use on the basis of locality, but were found significant different social anxiety.

Keywords: Problematic Internet Use, Social Anxiety, Gender and Locality 


\section{INTRODUCTION}

Having anxiety is normal human emotion. Everybody suffers from some degree of social anxiety from time to time-meeting new people, speaking before large groups and going on a first date. But having a social anxiety disorder which is suffering from a debilitating fear of social situations is not normal. When anxiety severely and negatively impacts the rest of a person's life, it may fall under the classification of anxiety disorder. Social anxiety is thought to be a normal human trait due to the frequency with which it occurs in nonclinical samples (Craske, Rapee, Jackel, \& Barlow 1989; Hofmann \& Roth 1996).

The Diagnostic and Statistical Manual of the American Psychiatric Association (APA) currently defines social anxiety disorder as follows:

1. Persistent fear of one or more social or performance situations in which the person is exposed to unfamiliar people or to possible scrutiny by others. The individual feelings of dread that he or she will act a way (or show nervousness side effects) that will humiliate and embarrassing.

2. Exposure to the feared situation almost invariably provokes anxiety, which may take the form of a situationally bound or situationally pre-disposed Panic Attack.

3. Individual perceives that this dread is preposterious or inordinate.

4. Feared situations are avoided or else are endured with intense anxiety and distress.

5. Avoidance, anxious anticipation, or distress in the feared social or performance situations interferes significantly with the person's normal routine, occupational (academic) functioning, or social activities or relationships, or there is marked distress about having the phobia.

6. Fear, anxiety, or avoidance is persistent, typically lasting 6 or more months.

7. Fear or avoidance is not due to direct physiological effects of a substance (e.g., drugs, medications) or a general medical condition not better accounted for by another mental disorder.

Social anxiety disorder is a risk factor for developing problematic internet use, and it is called 'internet addiction. Researchers suggest that problematic internet use may serve to worsen or reinforce social fears and avoidance of face to face social interactions (Lee \& Stapinski, 2012). Many individuals swing to the web keeping in mind the end goal to oversee disagreeable sentiments, for example, stress, dejection, and nervousness. Because excessive internet use can displace valuable time that people spend with family and friends who leads to smaller social 
circles and higher levels of Internet addiction also may contribute to anxiety and stress (Egger \& Rauterberg 1996). Those who suffer from anxiety and stress often have immense trouble interacting and communicating with others in a meaningful way. These human characteristics are viewed as important determinants of internet.

Problematic internet use often called internet addiction, has been defined in a variety of ways, but one commonly accepted definition described by Davis (2001) is the cognitive-behavioural model of problematic internet use. According to this model, using the internet to "regulate unpleasant moods, becoming attached to the social benefits the internet provides, and perceiving more interpersonal control online than offline" contributes to compulsive internet use, signs of withdrawal when offline, and negative psychological, interpersonal and occupational effects for such persons when not using the internet.

Research on problematic internet use has identified multiple personal factors as potential contributors or risk factors for this difficulty, including depression, loneliness, aggression, substance dependence, and shyness. Researchers have suggested that individuals with these characteristics might be more likely to be isolated socially in offline environments and therefore might turn to online communication for social contact. In particular, persons with social anxiety disorder often feel more comfortable using online communication methods versus face-to-face interactions due to high levels of fear and anticipation of treat and negative evaluation associated with live interactions.

\section{Internet usage in India- statistics \& facts}

India is the second biggest online market positioned just after China. By 2021, there will be around 635.8 million internet users in India. Despite the large base of internet users in India, only 26 percent of the Indian population accessed the internet in 2015.

Indians regularly swing to versatile web, as the extensive larger parts of the computerized population in India were mobile internet users in 2016. Furthermore, men dominated internet usage in India with 71 percent to women's 29 percent.

Mobile internet usage in individuals varies according to people's living areas. As of 2016, India had an estimate of 262 million mobile internet users living in urban communities, and 109 million living in rural areas. Indian population that access social networks is expected to jump from around 16.3percent of every 2016 to a little more than 25 percent. Face book is the most popular social networking site in the country. There were around 195 million face book users in India as 2016, placing India as the country with the largest face book user's base in the world. Other popular networks include whatsApp. 


\section{Number of internet users in India 2012-2016}

The total number of internet users on a total basis in June 2012 was 137 million and it is projected to reach around 402 million by the end of 2015. The number of monthly active internet users in India is set to reach 351 million in December 2015. The statistic shows the number of worldwide internet users in selected countries as of June 2017. China was positioned first with more than 738 million internet users; more than double the amount of third-positioned United States with 287 million internet users.

According to a recent report, there were 3.49 billion internet users around the world. Considering that the number of humans living on earth is presently estimated at some 8.5 billion, this means that over 41 percent of the world population is interconnected through the use of internet.

\section{State wise internet users in India}

Maharashtra has the highest number of internet subscribers in the country at 29.47 million, followed by Tamil Nadu, Andhra Pradesh and Karnataka. According to government data, India had at 28.01 million subscribers, while its neighbours Andhra Pradesh and Karnataka had 24.87 million and 22.63 million, respectively. Himachal Pradesh had the lowest number of subscribers at 3.02 million.

Tamil Nadu has the most elevated number of urban internet subscribers at 21.16 million, while UP (East) medium circle leads in terms of rural internet customer base at 11.21 million, Delhi had 20.59 million and Mumbai and Kolkata had 15.65 million and 9.26 million, respectively.

Analysis of 'Daily users' reveal that both in urban and rural India, the younger generations are the most profile users of internet. The gender ratio is slightly better in urban India, while both urban and rural India show almost similar ratios of university students.

More than 3.8 billion people around the world use the internet today, up to 38 million since January 2017. This one percent increase takes global internet penetration to 51 percent -in other words, people who don't use the internet are increasingly in the minority. The utilization of a mobile phone is currently normal around the universes, with very nearly $66 \%$ of the whole worldwide population now utilizing a versatile all the time. More and more of these users now own a smart phone too, and the latest data suggest that more than half of the world's population now uses one of these powerful devices. 


\section{MATERIALS AND METHOD}

\section{Objectives of the study:}

1. To find out the significant relationship between the levels of social anxiety and problematic internet use among university students.

2. To find out the significant difference between male and female university students in the levels of problematic internet use.

3. To find out the significant difference between male and female university students in the levels of social anxiety.

4. To find out the significant difference between the rural and urban university students in the levels of problematic internet use.

5. To find out the significant difference between the rural and urban university students in the levels of social anxiety.

\section{Hypotheses:}

1. There is no significant relationship between the levels of social anxiety and problematic internet use among university students.

2. There is no significant difference between male and female university students in the levels of problematic internet use.

3. There is no significant difference between male and female university students in the levels of social anxiety.

4. There is no significant difference between the rural and urban university students in the levels of problematic internet use.

5. There is no significant difference between rural and urban university students in the levels of social anxiety.

\section{Variables adopted for the present study:}

1. Dependent variables: Problematic Internet Use and Social Anxiety.

2. Independent variables: Gender and Locality.

Sample: 200 samples were collected from Tripura University.

\section{Instruments Used}

Problematic Internet Use Questionnaire developed by Tatcher \& Goolam, 2005 was used for the measurement of problematic internet use. These twenty items were specifically designed to asses self-reported problematic internet use. Respondent were asked to indicate on a 5-Likerttype format (from "never" to "always") the extent of various symptoms or behaviour of 
problematic internet use, where 1 is an indication of low problematic internet use and 5 indicates of high problematic use. The PIUQ therefore assesses problematic internet use on a scale 20 to 100 (where 100 is an indication of having problematic internet use). The PIUQ demonstrated good reliability.

Social Anxiety Questionnaire for Adults (SAQ-A30) developed by Callallo, Salazar, Irurtia, Arias and CISO-A Research Team, 2010 were used for the measurement of social anxiety. Each item of the SAQ could be answered on a five-point Likert scale to indicate the level of unease, stress or nervousness in response to each social situation: $1=$ Not at all or very slight, $2=$ Slight, 3=Moderate, 4=High, 5=Very high or extremely high. It has five dimensions (factors): 1) Speaking in public/talking with people in authority, 2) interactions with the opposite sex, 3) assertive expression of annoyance, disgust or displeasure, 4) criticism and embarrassment, and 5) interactions with strangers. The cronbach's alpha for the whole questionnaire was .91 and splithalves reliability coefficient (Guttman) was .93.

\section{Procedure of data collection}

The University student's data were selected purposively from Tripura University students of Agartala, (Tripura). First of all permission has been taken from the authority of the University. After getting permission dates and time were fixed according to their convenience for collection of data. At first a proper rapport was established with the respondents. Then the sociodemographic information's were collected from each respondent. Later the scales of problematic internet use and social anxiety were administrated on the respondents. In case of problematic internet use five-point Likert scale format (from never to always) the respondent was instructed to choose 1 out of the 5 options according to respondents. In case of social anxiety the respondent was instructed to choose 1 out of 5 options. In this manner 200 data were collected from the students of the Tripura University.

\section{Data and analysis}

In order to compare the relationship between social anxiety and problematic internet use among university students. The Mean scores and SDs were found out t-value and p-value was calculated. The Mean scores, SDs and t-value of problematic internet use and social anxiety of various dimensions are given below tables.

Table 1: Showing the relationship between social anxiety and problematic internet use among university students

\begin{tabular}{lll}
\hline & Problematic Internet Use & Level of Significant \\
\hline Social Anxiety & $.182^{* *}$ & Significant \\
\hline
\end{tabular}


** Correlation is significant at the 0.01 level.

The present study revealed that social anxiety is positively related with problematic internet use. The obtained value (.182) was found and it is Significant at 0.01 level. Therefore it can conclude that social anxiety is an influenced variable in problematic internet use. Therefore the formulated hypothesis that, there is no significant relationship between the levels of problematic internet use and social anxiety and university students is rejected.

Table 2: Showing Mean, Standard Deviation, $t$-value of problematic internet use levels on the basis of gender

\begin{tabular}{lllllll}
\hline Gender & N & Mean & S.D & t-value & p-value & L.S \\
\hline Male & 165 & 55.25 & 11.77 & & & \\
Female & 35 & 48.57 & 10.28 & 3.40 & .001 & Sig \\
\hline
\end{tabular}

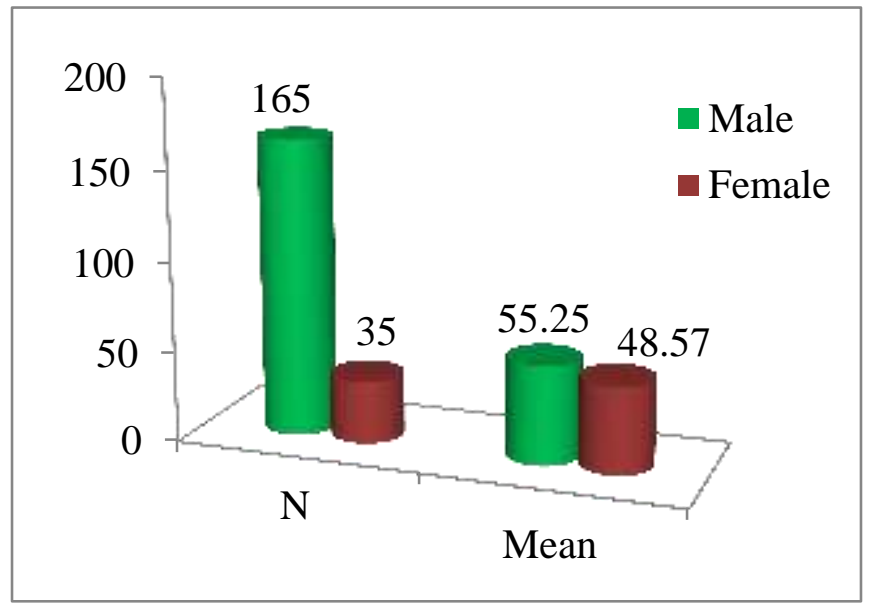

Figure 1: Graphical represent of table 2

According to table 2, indicates that there is a significant difference between male and female of problematic internet use on the basis of gender. Mean value of male students is 55.25 and mean value of female students is 48.57 respectively, and their S.D is 11.77 and 10.28 and t-value is 3.40 respectively. The obtained p-value .001 is statistically significant. It reveals that Mean value of male students is higher than the female students. Therefore the framed hypothesis that, there is no significant difference between males and females problematic internet use on the basis of gender is rejected.

Table 3: Showing Mean, Standard Deviation, $t$-value of social anxiety levels on the basis of gender.

\begin{tabular}{lllllll}
\hline Gender & N & Mean & S.D & t-value & p-value & Level of Significant \\
\hline Male & 165 & 94.45 & 22.03 & & & \\
Female & 35 & 85.26 & 18.45 & 2.58 & .012 & Significant \\
\hline
\end{tabular}




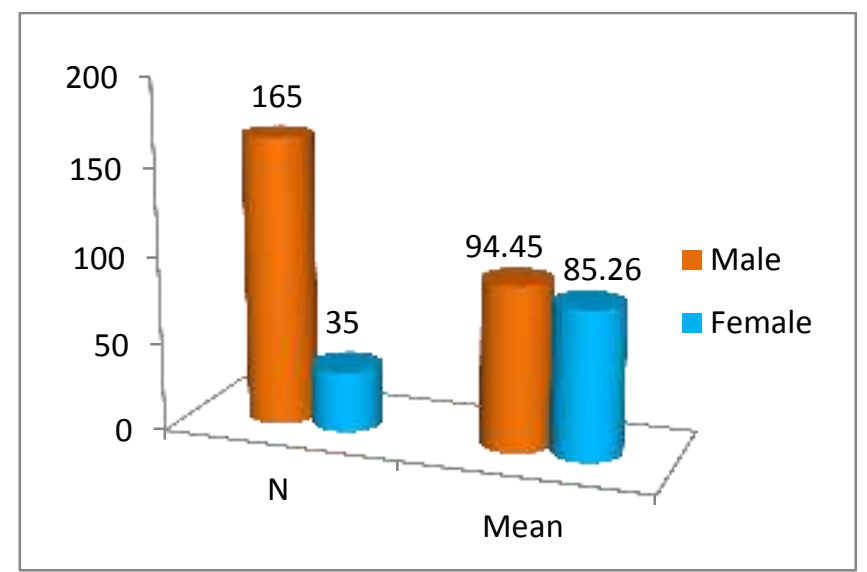

Figure 2: Graphical represent of table 3

According to table 3, indicates that there is no significant difference between male and female of social anxiety on the basis of gender. Mean value of male students is 94.45 and female students is 85.26 respectively, and S.D is 22.03 and 18.45 respectively and their t-value is 2.58 . The obtained p-value .012 is statistically significant. It reveals that Mean value of male students is higher than the female students. Therefore the formulated hypothesis that, there is no significant difference between males and females of social anxiety is rejected.

Table 4: Showing Mean, Standard Deviation, $t$-value of problematic internet use levels on the basis of locality

\begin{tabular}{lllllll}
\hline Locality & $\mathbf{N}$ & Mean & S.D & t-value & p-value & Level of Significant \\
\hline Rural & 75 & 53.82 & 12.25 & & & \\
Urban & 125 & 54.53 & 11.52 & .41 & .68 & Not Significant \\
\hline
\end{tabular}

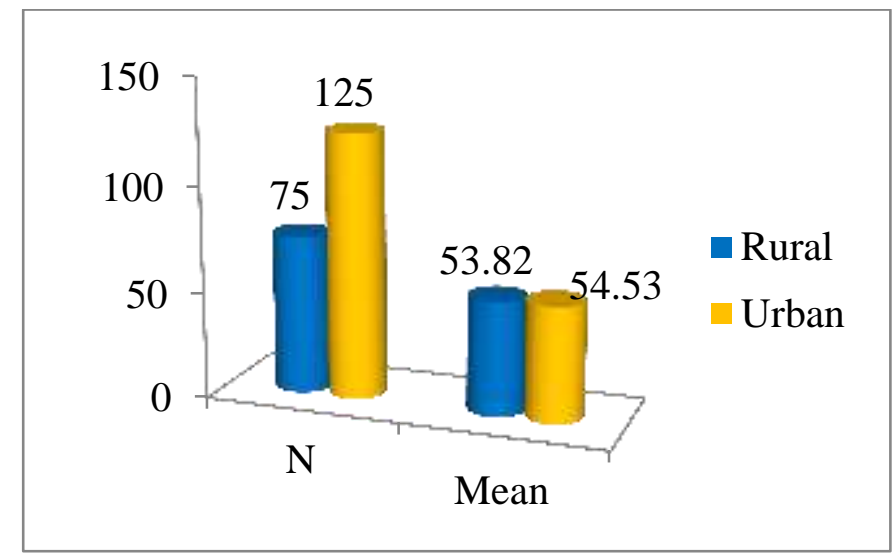

Figure 3: Graphical represent of table 4

Table 4, indicates that there is no significant difference between rural and urban students of problematic internet use on the basis of locality. Mean value of urban students is 54.53 and mean value of rural students is 53.82 respectively, and S.D is 12.25 and 11.52 and t-value is .41 
respectively. The obtained p-value .68 is not significant. This reveals that the problematic internet use does not differ on the basis of their locality. Therefore the formulated hypothesis that, there is no significant difference between rural and urban students of problematic internet use on basis of locality is accepted.

Table-5: Showing Mean, Standard Deviation, $t$-value of social anxiety levels on the basis of locality.

\begin{tabular}{lllllll}
\hline Locality & N & Mean & S.D & t-value & p-value & Level of significant \\
\hline Rural & 75 & 92.86 & 21.91 & & & \\
Urban & 125 & 92.81 & 21.64 & .01 & .98 & Not Significant \\
\hline
\end{tabular}

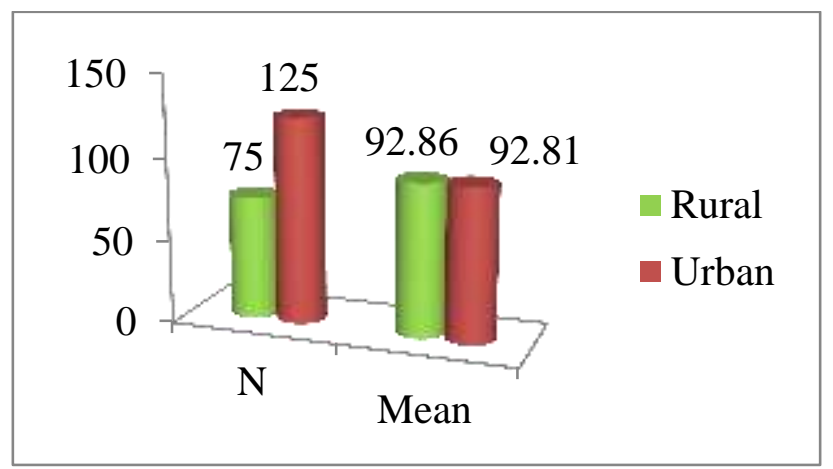

Figure 4: Graphical represent of table 5

According to table 5, indicates that there is no significant difference between rural and urban students of social anxiety on the basis of locality. Mean value of rural students is 92.81 and mean value of urban students is 92.8 and S.D is 21.91 and 21.64 respectively. And t-value is .01 respectively. The obtained p-value .98 is statistically not significant. It reveals that the social anxiety does not differ on the basis of locality. Therefore the formulated hypothesis that, that there is no significant difference between rural and urban students of social anxiety on the basis of locality is accepted.

\section{Findings}

The following findings are arrived from the statistical analysis: They are

1. There is a positive and significant relationship between social anxiety and problematic internet use among university students.

2. Male students have higher level of problematic internet use than female students.

3. Male students have higher social anxiety than the female students.

4. No significance difference between rural and urban students of problematic internet on the basis of locality 
5. No significance difference between rural and urban students of social anxiety on the basis of locality.

\section{Limitation of the study}

The present study has been limited only to the University students studying the Arts and Science stream, also restricted only to Tripura University in Agartala West District.

\section{Implications:}

1. Finding of this study leads to suggest some internet awareness and educational awareness program for University students in order to minimize their levels of problematic internet use and to create positive attitude for social anxiety.

2. Through proper guidance and counselling, of the university students and their anxiety should be found out, to find solutions to their problems.

3. The teachers should give to chance every students free group discussion and should provided extra curriculum activities.

4. The university should conduct seminars and workshop and creating tuned into causes effects of internet addiction and anxiety.

5. The students families should concerned that their loved one might be at risk for problematic internet use or might already show signs of internet addiction, and then they should communicate with the socially anxious individual about these concerns and should collaborate with a mental health professional to help address the potential problem. Families and supporters of persons with social anxiety disorder should increase their awareness of the potential risks of internet addiction in their loved ones with social anxiety disorder in order to help monitor for and safeguard against such risks when possible.

\section{CONCLUSION}

In this study it is concluded that social anxiety is the influential variable in problematic internet use. In the digital and fast-placed life of today, the most affected and threatened are the youth. Anxiety effects their mental health and physical health. It has become very important to know their level of social anxiety and level of problematic internet use. Furthermore, research has established a clear connection between social anxiety and problematic internet use but little is known about the specific factors involved in this connection. This study result found that social anxiety related to problematic internet use among university students and that higher level of social anxiety corresponded to higher rates of problematic internet use. This study also found 
that male students having problematic internet use than female students. And also found that male students having higher social anxiety than female students. It means that male students are lack of social interaction and this is the reason they are addicted to internet as compare to female students. Heavy usage of internet may lead to decrease visiting friends and family. According to Caplan's (2010) model, the reported preference of online social interaction may indicate feeling better or safer online than in a face-to-face interaction. Female students have better communication skills than males with males perhaps more inclined to develop a preference for online social interaction. Social support programs as well as individual and group work could be suggested for both male and female students.

\section{REFERENCES}

1. American Psychiatric Association (1994). Diagnostic and statistical manual of mental disorders ( $4^{\text {th }}$ ed.; DSM 1V). Washington DC: American Psychiatric Association.

2. Caplan, S. E. (2005). A social skill account of problematic internet use. Journal of Communication, 722, 2-20.

3. Ceyhan, A. A. (2011). University students' problematic internet use and communication skills according to the internet use purposes. Journal of Educational Sciences: Theory and Practice, 11(1), 66-77.

4. Caballoa, V. E., Ariasb, B., Salazara, I. C., Irurtiab, M. J., \& Hofmance, S. G. (2015). Psychometric properties of an innovative self-report measure: The social anxiety questionnaire for adults. Journal of HHS public Access, 27(3), 997-1012.

5. Durak, M., \& Senol-Durak, E. (2013). Associations of social anxiety and depression with cognitions related to problematic internet use in youths. International Journal of Education and Science, 38(169), 1-11.

6. Islam, M. A, \& Hossain, M. Z. (2016). Prevalence and risk factors of problematic internet use and the associated. Asian Journal of Gambling Issues and Public Health, 6(11), 114115.

7. Khan, R. B., Salim, B. M., Hussain, A., \& Haseeb, M. (2014). The relationship between internet addiction and anxiety among students of university of Sargodha. International Journal of Humanities and Social Science, 4(1), 1-6.

8. Kawa, M. H., \& Shafi, H. (2015). Evaluation of Internet Addiction Psychological Distress among University Students. To International Journal of Modern Social Sciences, $4(1), 29-41$ 
9. Spada, M. M. (2014). An overview of problematic internet use (2014). International Journal of Addictive Behaviours, 39(1), 3-6.

10. Loan F. A. (2011). Internet use by rural and urban college students: A Comparative study. Journal of Library and Information Technology, 31(6), 431-436.

11. Lee \& Stapinski (2012). Seeking safety on the internet: relationship between social anxiety and problematic internet use. International Journal of Anxiety Disorder, 26(1), 197-205

12. Odaci, H., \& Kalkan, M. (2010). Problematic internet use, loneliness and dating anxiety among young adult's university students. International Journal of Computers and Education, 55, 1091-1097.

13. Ozgur, H., Demiralay, T., \& Demiralay, I. (2014). Exploration of problematic internet and loneliness among distance education students. Journal of Distance Education, 15(2), 1-6.

14. Panicker, J. \& Sachdev R. (2014). Relations among loneliness, depression, anxiety, stress and problematic internet use. Journal of International of Research in Applied, Natural and Social Sciences, 2(9), 1-10.

15. Serin, N. B. (2011). An examination of predictor variables for problematic internet use. Journal of Educational Technology, 10(3), 1-9.

16. Stefan, G. H., \& Walton, T. R. (1996). Issues related to social anxiety among controls in social phobia Research. Behaviour Therapy. 27, 79-91

17. Thatcher, A. \& Goolam, S. (2005). Development of psychometric properties of the problematic internet use questionnaire. South African J Psychology, 35(4), 793-809

18. Weinstein, A., Dorani, D., Elhadif, R., Bukuvza, Y., \& Yarmulnik A. (2015). Internet addiction is associated with social anxiety in young adults. Annals of clinical psychiatry, 27(1), 30 .

\section{AJPHR is}

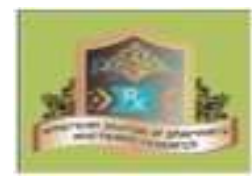

Peer-reviewed

monthly

Rapid publication

Submit your next manuscript at

editor@ajphr.com / editor.ajphr@gmail.com 